cessful in spreading the word. "It's been really hard to capture public attention," he says, "and I think that is what Gore has really done."

Susan Solomon, a senior scientist with the National Oceanic and Atmospheric Administration and co-chair of the IPCC's first working group, calls the prize a "wonderful victory for science" and credits Gore with delivering the message to the public. "I love the movie. I really do," Solomon says. "I think his goal is to make people aware, and I think that is a very good goal. I don't think he has tried to promote a political agenda." Dan Schrag, a geochemist at Harvard University, while agreeing that the prize for Gore was well deserved, is not so sanguine about the politics. "The only concern I have is that Gore has helped make the climate issue a partisan issue in the United States, and that is not true in other parts of the world."

Predictably, the prize has increased speculation that Gore will make another run for the White House, a possibility that Gore has repeatedly played down but never entirely ruled out.

Quirin Schiermeier and Jeff Tollefson See Editorial, page 755.

\section{Happy birthday}

This year's Nobel Prize in Chemistry was awarded to Gerhard Ertl (pictured) on 10 October, which just happened to be his seventy-first birthday. Ertl developed ways of applying spectroscopic techniques to tease out the mechanisms of reactions at surfaces, such as the Haber-Bosch synthesis of ammonia. He retired as director of the Max Planck Society's Fritz Haber Institute in Berlin in 2004. The prize committee said his work "provided the scientific basis of modern surface chemistry".

Chemists welcomed the award of this year's prize to a 'proper chemist', as several recent Nobels have gone to research that might in many eyes be seen more as biology. Some, though, have expressed surprise that the award was given to Ertl alone, and not shared with fellow surface chemist Gabor Somorjai of the University of California, Berkeley. When asked about this, Somorjai replied: "It's a very well deserved prize. Professor Ertl is a very good scientist, a good colleague and a good friend." Daniel Cressey

For full coverage see http://tinyurl.com/26nyxh

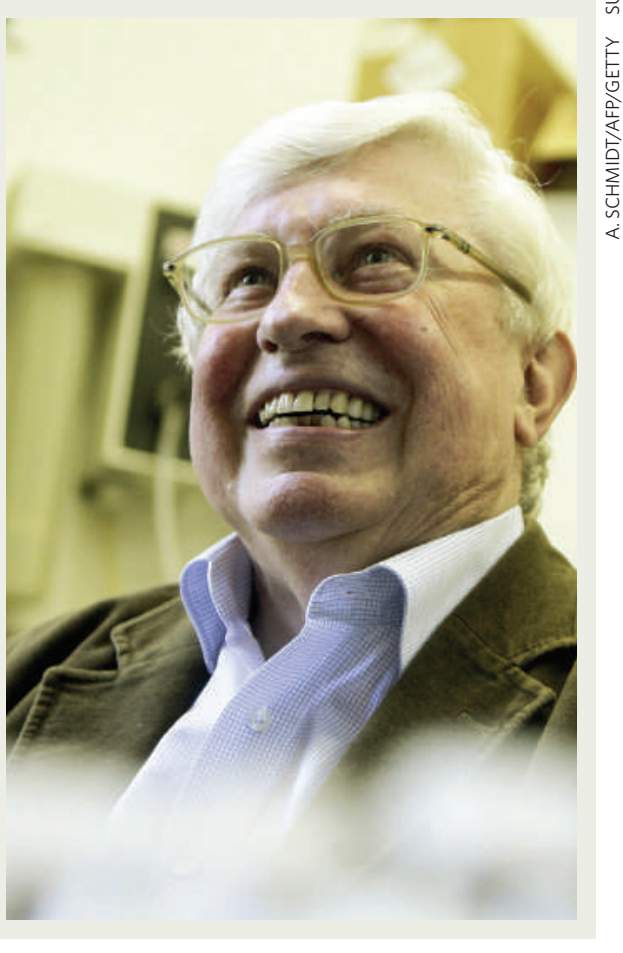

